\title{
Application of in Utero Electroporation of G-Protein Coupled Receptor (GPCR) Genes, for Subcellular Localization of Hardly Identifiable GPCR in Mouse Cerebral Cortex
}

\author{
Nam-Ho Kim ${ }^{1,4,5}$, Seunghyuk Kim ${ }^{1,5}$, Jae Seung Hong ${ }^{2}$, Sung Ho Jeon ${ }^{3}$, and Sung-Oh Huh ${ }^{1, *}$
}

\begin{abstract}
Lysophosphatidic acid (LPA) is a lipid growth factor that exerts diverse biological effects through its cognate receptors $\left(\mathrm{LPA}_{1}-\mathrm{LPA}_{6}\right)$. LPA 1 , which is predominantly expressed in the brain, plays a pivotal role in brain development. However, the role of $\mathrm{LPA}_{1}$ in neuronal migration has not yet been fully elucidated. Here, we delivered LPA $_{1}$ to mouse cerebral cortex using in utero electroporation. We demonstrated that neuronal migration in the cerebral cortex was not affected by the overexpression of LPA . $^{\text {. }}$ Moreover, these results can be applied to the identification of the localization of LPA 1 . The subcellular localization of $\mathrm{LPA}_{1}$ was endogenously present in the perinuclear area, and overexpressed $\mathrm{LPA}_{1}$ was located in the plasma membrane. Furthermore, $\mathrm{LPA}_{1}$ in developing mouse cerebral cortex was mainly expressed in the ventricular zone and the cortical plate. In summary, the overexpression of LPA did not affect neuronal migration, and the protein expression of LPA $_{1}$ was mainly located in the ventricular zone and cortical plate within the developing mouse cerebral cortex. These studies have provided information on the role of $\mathrm{LPA}_{1}$ in brain development and on the technical advantages of in utero electroporation.
\end{abstract}

\section{INTRODUCTION}

Lysophosphatidic acid (LPA; 1-acyl-sn-glycerol-3-phosphate), which is a phospholipid growth factor, exerts diverse biological effects on neuronal cells, including proliferation, differentiation, survival, morphological change, and migration (Choi et al.,

${ }^{1}$ Department of Pharmacology, College of Medicine, Institute of Natural Medicine, ${ }^{2}$ Department of Physical Education, ${ }^{3}$ Department of Life Science and Center for Aging and Health Care, Hallym University, Chuncheon 200-702, Korea, ${ }^{4}$ Present address: Department of Neurosurgery, Cedars-Sinai Medical Center, Los Angeles, CA, 90048, USA, ${ }^{5}$ These authors contributed equally to this work.

*Correspondence: sOhuh@ @allym.ac.kr

Received 5 June, 2014; revised 30 June, 2014; accepted 30 June, 2014; published online 31 July, 214

Keywords: cerebral cortex, GPCR, in utero electroporation, lysophosphatidic acid, lysophosphatidic acid receptor-1
2010; Ishii et al., 2004; Moolenaar et al., 2004; Yung et al., 2014). LPA signals through at least six specific membranebound $\mathrm{G}$ protein-coupled receptors (GPCRs) that are designated as $\mathrm{LPA}_{1} / \mathrm{Vzg}-1 / \mathrm{Edg} 2, \mathrm{LPA}_{2} / \mathrm{Edg} 4, \mathrm{LPA}_{3} / \mathrm{Edg}$, LPA 4 /p2y9/ GPR23, LPA 5 /GPR92, and LPA 6 /p2y5 (An et al., 1998; Bandoh et al., 1999; Hecht et al., 1996; Kotarsky et al., 2006; Lee et al., 2006; Noguchi et al., 2003; Pasternack et al., 2008). The lysophosphatidic acid receptor-1 (LPA $)_{1}$, which was the first LPA receptor identified (Hecht et al., 1996), was found to be involved in LPA signaling in the development of the central nervous system through studies involving the targeted deletion of LPA $_{1}$ (Contos et al., 2000; Estivill-Torrus et al., 2008; MatasRico et al., 2008). This receptor was shown to be expressed in the neurogenic region of the embryonic neocortical region, which is called the ventricular zone (VZ) (Hecht et al., 1996).

Following the identification of $\mathrm{LPA}_{1}$, studies were directed towards understanding the role of LPA in the cortical development of mice. When LPA was not present in the VZ, neural progenitor cells underwent proliferation, differentiation, and cell death. In the presence of LPA, cell rounding and retraction fiber formation were observed in mouse cortical primary cells (Fukushima et al., 2000). In addition, LPA signaling regulated the formation of cerebral cortical folds that resemble gyri by affecting proliferation, differentiation, and cell survival during embryonic development (Kingsbury et al., 2003). The mouse embryonic cerebral cortex exhibited gene expression profiles of two $L P A$ receptors $\left(L^{2} A_{1}\right.$ and $\left.L P A_{2}\right)$, suggesting important roles of $\mathrm{LPA}_{1}$ and $\mathrm{LPA}_{2}$ in cerebral cortical development (Kingsbury et al., 2003). However, in many LPA studies, it has been difficult to localize the LPA receptor in vivo.

Formerly, studies of the functional consequence and expression pattern of the $\mathrm{LPA}_{1}$ receptor were performed with in situ hybridization and reverse transcription polymerase chain reaction analysis (Cheng et al., 2009; Hecht et al., 1996; Kim et al. 2006; Spohr et al., 2008; Sun et al., 2010).

Since LPA1 receptors, like all G protein-couple receptors, cannot be easily visualized by an antibody, it is hard to discern the actual localization of the protein. Some papers have used $\mathrm{LPA}_{1}$ antibodies to show the subcellular localization and expression of $\mathrm{LPA}_{1}$. These studies examined antibody specificity by blocking the signal with the overexpression of antisense LPA receptors or LPA receptor peptides (Gobeil et al., 2003; Liszewska et al., 2009; Moughal et al., 2004; Waters et al., 2006; 
Zheng et al., 2001). However, these studies were not conclusive.

In this study, we ectopically overexpressed $\mathrm{LPA}_{1}$ in the developing mouse cerebral cortex using in utero electroporation. $\mathrm{LPA}_{1}$ overexpressed mice did not show obvious abnormalities in cerebral cortical development. In addition, we examined the subcellular localization and tissue distribution of $\mathrm{LPA}_{1}$ in embryonic brain. The subcellular localization of $\mathrm{LPA}_{1}$ in $\mathrm{LPA}_{1}$ overexpressing cells was mainly located in the plasma membrane and endogenously located in the perinuclear area. The tissue distribution of $\mathrm{LPA}_{1}$ was mainly observed in the VZ and cortical plate (CP) of the embryonic cortex. Our studies revealed the subcellular localization of $\mathrm{LPA}_{1}$ in vivo and showed the technical advantage of antibody validation using in utero electroporation.

\section{MATERIALS AND METHODS}

\section{Animal}

Pregnant mice of C57BL/6N strain were purchased from Orient Bio (Korea). Stage E0.5 was defined as noon on the day of the vaginal plug. Fetuses at E13.5, E15.5, and E17.5 were used for experiments.

\section{Materials}

All chemicals used were of analytical grade if not stated otherwise. Antibody to $\beta$-actin was obtained from Cell Signaling Technology (USA). Antibodies to $\mathrm{LPA}_{1}$, and green fluorescent protein (GFP) were purchased from Abcam (UK). Dulbecco's modified Eagle's Medium (DMEM), Opti-MEM I reduced-serum medium, 100 unit penicillin/100 $\mu \mathrm{g}$ streptomycin, fetal bovine serum (FBS), lipofectamine 2000, and DAPI were obtained from Invitrogen (USA).

\section{Cell culture}

TR cells which is derived from neocortical neuroblast cells infected with the oncogenes Large $\mathrm{T}$ and vras (Chun and Jaenisch, 1996) were maintained as monolayer cultures in OptiMEM I reduced-serum medium supplemented with $2.5 \%$ heatinactivated fetal bovine serum, $20 \mathrm{mM}$ glucose, $55 \mu \mathrm{M}$ 2mercaptoethanol, and 100 unit penicillin/ $100 \mu \mathrm{g}$ streptomycin. B103 rat neuroblastoma cells were maintained in DMEM supplemented with $10 \%$ FBS. B103 cells were transiently transfected with pCAGIG or pCAGIG-LPA1 expression plasmid using the Lipofectamine 2000 reagent. After $24 \mathrm{~h}$, the fluorescent images were acquired with an inverted microscope (IX70; Olympus).

\section{Isolation of total protein and Western blot analysis}

TR cells were lysed in lysis buffer (50 mM Tris-HCl, pH 7.5, 150 $\mathrm{mM} \mathrm{NaCl}, 1 \mathrm{mM}$ ethylene glycol tetraacetic acid (EGTA), $1 \mathrm{mM}$ ethylenediaminetetraacetic acid (EDTA), 1\% Triton X-100, 1 $\mathrm{mM} \mathrm{Na} 3 \mathrm{VO} 4,5 \mathrm{mM} \mathrm{NaF}$, and protease inhibitor cocktail). After incubation on ice for $30 \mathrm{~min}$, the lysates were centrifuged $(15,000 \times g, 15 \mathrm{~min})$. Supernatants were collected and protein concentrations were determined by Bradford assay (Bio-Rad, USA). Equal amounts of protein were boiled and separated by sodium dodecyl sulfate polyacrylamide gel electrophoresis (SDS-PAGE) transferred to polyvinylidene difluoride membranes (Millipore, USA), and blocked with $5 \%$ non-fat milk. Membranes were incubated in primary antibody overnight at $4^{\circ} \mathrm{C}$. Membranes were then washed in TBST (10 mM Tris, 140 $\mathrm{mM} \mathrm{NaCl}, 0.1 \%$ Tween $20, \mathrm{pH} 7.6$ ), incubated with appropriate secondary antibody, and washed again in TBST. Bands were visualized by chemiluminescence and exposed to X-ray film.

\section{DNA constructs}

pCAGIG-LPA ${ }_{1}$ expression vector design was based on the pCAGIG vector. The PCAGIG vector, which contains the IRESEGFP cDNA under the control of the CMV enhancer and chick $\beta$-actin promoter, was a gift from Dr. C. Cepko (Matsuda and Cepko, 2004). The full coding sequence for murine $\mathrm{LPA}_{1}$ was obtained by reverse transcription PCR. Total RNA was prepared from the cerebellum of adult C57BL/6N mice using TRIzol reagent (Invitrogen). Total RNA $(2 \mu \mathrm{g})$ was converted to cDNA using AMV reverse transcriptase (Promega, USA). The coding regions of mouse $\mathrm{LPA}_{1}$ were PCR amplified from cDNA with the following $5^{\prime}$-EcoRI-mLPA $A_{1}$ and $3^{\prime}-$ Notl-mLPA $A_{1}$ primer sets: 5'-CCGGAATTCATGGCAGCTGCCTCTACTT-3', and 5'GAGAGCGGCCGCTACACGGTCACCCCAGA-3'. The PCR product was subcloned into the pCAGIG vector at EcoRI and Notl sites. pCAGIG-LPA ${ }_{1}$ construct was confirmed by automated sequencing.

\section{In utero electroporation}

Timed-pregnant C57BL/6N females were anesthetized at stage embryonic day 13.5 (E13.5) with isoflurane (4\% during induction, $2.5 \%$ during surgery), and the uterine horns were exposed by way of a laparotomy. The $1 \mu \mathrm{l}$ of expression vector $(4 \mu \mathrm{g} / \mu \mathrm{l}$ for PCAGIG and pCAGIG-LPA 1 constructs) in phosphate buffered saline (PBS) containing $0.05 \%$ fast green (Sigma-Aldrich, USA) was injected into the lateral ventricle of the embryo using a glass capillary with a length of $90 \mathrm{~mm}$ and a diameter of 1 $\mathrm{mm}$ (GD-1; Narishige, Japan). Electroporation was performed with a Tweezertrodes (diameter, $5 \mathrm{~mm}$; BTX, USA) with 5 pulses of $45 \mathrm{~V}$ for 50 millisecond duration and 950 millisecond interval using a square-wave pulse generator (ECM 830; BTX). The uterine horns were then returned into the abdominal cavity, the wall and skin were sutured, and embryos were allowed to continue their normal development.

\section{Immunohistochemistry}

Electroporated embryonic brains were fixed with $4 \%$ paraformaldehyde (PFA) at $4^{\circ} \mathrm{C}$ for $2 \mathrm{~h}$. Brains were cryoprotected in $30 \%$ sucrose $/ 1 \times$ PBS at $4^{\circ} \mathrm{C}$ overnight and embedded in Tissue-Tek OCT (Sakura Finetek, USA). Cryosections $(10 \mu \mathrm{m})$ were collected on MAS-coated glass slides (Matsunami Glass, Japan). Sections on glass slides were treated with heat in citrate buffer $(10 \mathrm{mM}, \mathrm{pH} 6.0)$ at $95^{\circ} \mathrm{C}$ for $5 \mathrm{~min}$. Samples were blocked in PBST containing 10\% normal goat serum. The sections were incubated with primary antibodies against GFP (Abcam) $(1: 1000)$ and $\mathrm{LPA}_{1}$ (Abcam) $(1: 1000)$ overnight at $4^{\circ} \mathrm{C}$ and then incubated in Alexa 488 and Alexa 568 conjugated secondary antibodies (Invitrogen) (1:1000) for one hour at room temperature. After washing, the specimens were mounted onto cover slips using Vectashield (Vector Laboratories, USA). The fluorescent images were acquired with a laser scanning confocal microscope (LSM510; Zeiss). For identify distribution of the GFP positive cells, images were converted gray values and normalized to background staining. Images were divide 10 equal bins spanning the cortical thickness and measured by ImageJ program (NIH).

\section{In situ hybridization}

Cryosections $(18 \mu \mathrm{m})$ were collected on MAS-coated glass

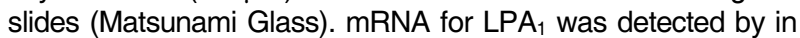
situ hybridization using digoxygenin (DIG)-labeled antisense riboprobes. The sections were treated with proteinase $\mathrm{K}$ (1 


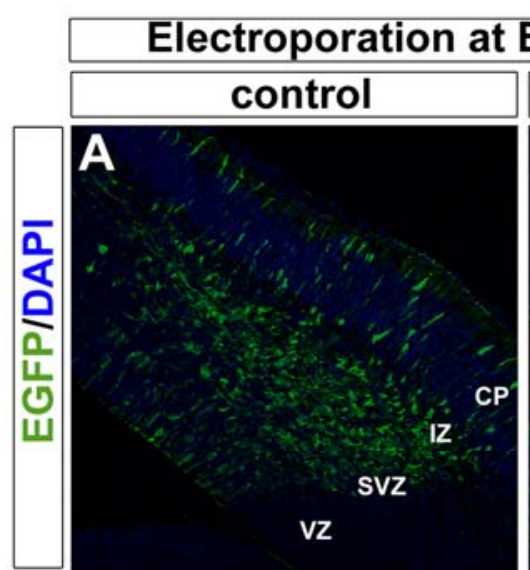

\section{E13.5}
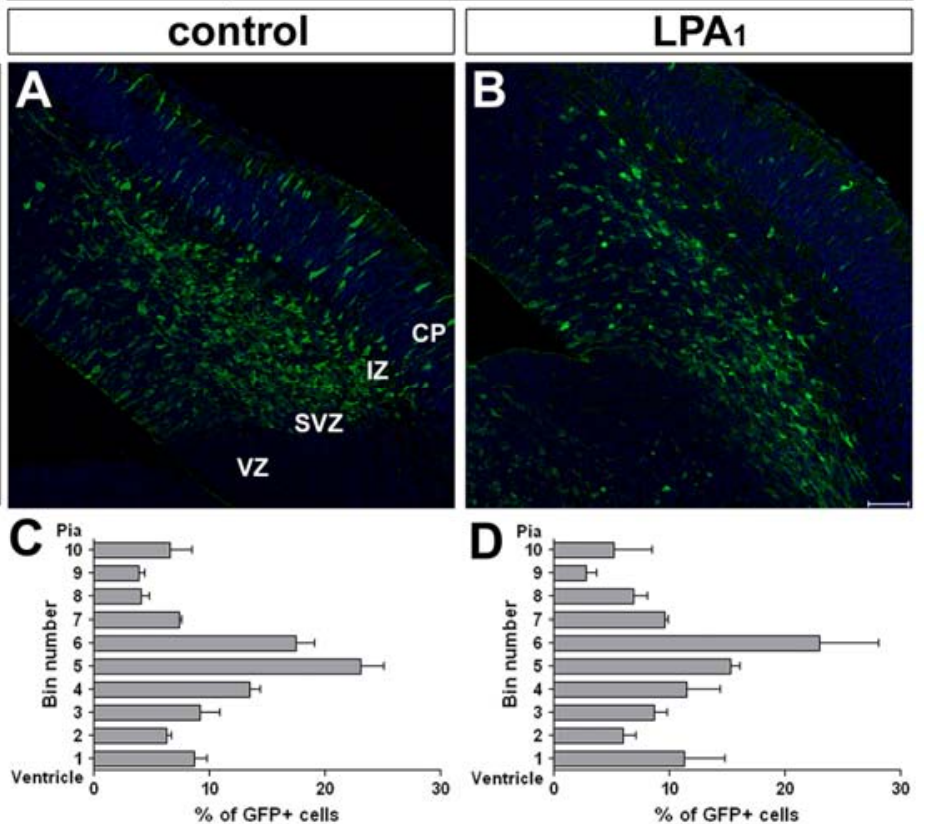

Fig. 1. In vivo overexpression of $\mathrm{LPA}_{1}$ protein by in utero electroporation. Confocal images of coronal sections of cortices of embryonic (E13.5) mice transfected by in utero electroporation with control (A, C; expressing EGFP; pCAGIG) or $\mathrm{LPA}_{1}(\mathrm{~B}, \mathrm{D}$; expressing EGFP and $\mathrm{LPA}_{1}$; pCAGIG-LPA 1 ) constructs that were harvested $48 \mathrm{~h}$ post electroporation and immunostained for GFP. Distribution of GFP positive cells in 10 bins spanning cortical thickness are shown as histograms (C, D). DAPI staining was used as a nuclear marker. CP, cortical plate; IZ, intermediate zone; SVZ, subventricular zone; VZ, ventricular zone. Scale bar, $100 \mu \mathrm{m}$.

$\mu \mathrm{g} / \mathrm{ml}$, 5-30 min, room temperature) and hybridized with 0.3 $\mu \mathrm{g} / \mathrm{ml}$ riboprobe in a hybridization buffer (50\% formamide, 20 $\mathrm{mM}$ Tris- $\mathrm{HCl}$ at $\mathrm{pH} 7.5,600 \mathrm{mM} \mathrm{NaCl}, 1 \mathrm{mM}$ EDTA, $10 \%$ dextran sulfate, $200 \mu \mathrm{g} / \mathrm{ml}$ yeast tRNA, $1 \times$ Denhardt's solution, $0.25 \%$ SDS) at $65^{\circ} \mathrm{C}$ overnight. The sections were washed three times with $1 \times \mathrm{SSC}$ containing $50 \%$ formamide at $65^{\circ} \mathrm{C}$, followed by maleic acid buffer $(0.1 \mathrm{M}, \mathrm{pH} 7.5)$ containing $0.1 \%$ Tween 20 and $0.15 \mathrm{M} \mathrm{NaCl}$. DIG-labeled probe was visualized by overnight incubation of the sections with anti-DIG antibody conjugated to alkaline phosphatase $(1: 2,000$; Roche, USA) and NBT/BCIP reaction. The open reading frame of Lpar1 antisense riboprobe was synthesized using a digoxygenin-labeled riboprobe with T7 RNA polymerase and a DIG-RNA labeling mix according to the manufacturer (Roche). The Lpar1 riboprobe was a gift from Dr. Jerold Chun (The Scripps Research Institute).

\section{RESULTS}

Characterization of the spatiotemporal-specific LPA overexpressing mouse cerebral cortex

To evaluate the importance of $\mathrm{LPA}_{1}$ in neuronal migration in the developing cerebral cortex, we examined the overexpression of $\mathrm{LPA}_{1}$ in the VZ by in utero electroporation. First, we made a vector containing $\mathrm{LPA}_{1}$ and tested it in $\mathrm{B} 103$ rat neuroblastoma cells. pGAGIG-LPA ${ }_{1}$ encoding [ $\mathrm{LPA}_{1}$ /enhanced green fluorescent protein (EGFP)] - transfected cells displayed a flattened and more migratory morphology compared with PCAGIG (encoding EGFP)-transfected cells (data not shown). We injected a construct encoding EGFP or LPA $\mathrm{A}_{1} / \mathrm{EGFP}$ into the lateral ventricle of E13.5 mouse embryos and transferred it into neuronal progenitor cells in the VZ by in utero electroporation (Saito, 2006). After allowing normal in vivo embryonic development, immunohistochemistry for GFP was performed on coronal brain sections obtained from E15.5 mice. The expression of EGFP was

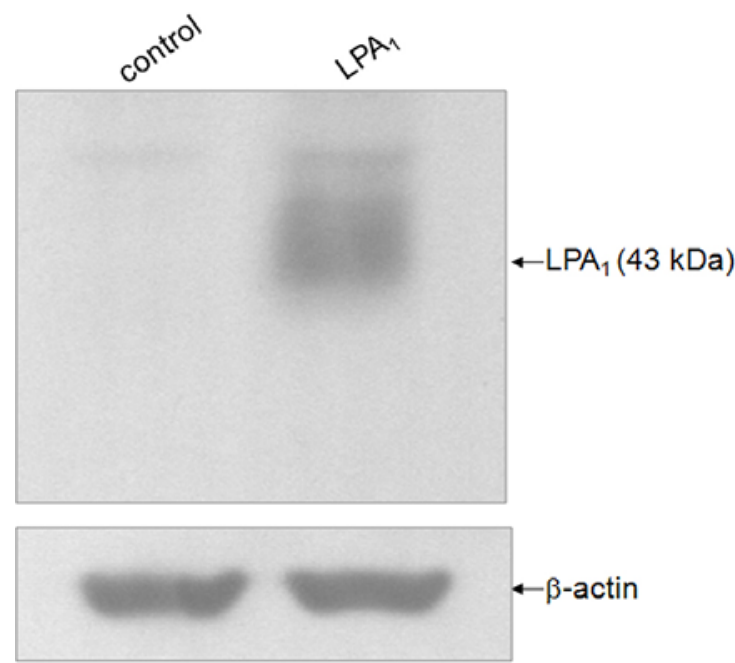

Fig. 2. Western blot analysis of $L P A_{1}$ proteins in $T R$ neocortical neuroblast cells. TR cells were transiently transfected with control (expressing EGFP) or LPA ${ }_{1}$ (expressing EGFP and LPA $_{1}$ ) constructs. Twenty-four hours post-transfection, the cells were lysed, probed with an anti-LPA ${ }_{1}$ antibody and a $\beta$-actin antibody, and analyzed by Western blots.

detectable in many neurons of mice transfected with EGFP (Fig 1A) or with $\mathrm{LPA}_{1}$ and EGFP (Fig. 1B). In EGFP-transfected control (Figs. $1 \mathrm{~A}$ and $1 \mathrm{C}$ ), transfected cells were mainly located in the subventricular zone (SVZ) and intermediate zone (IZ), and some populations entered the cortical plate $(C P)$. These neuronal migration patterns correlated with previously reported results (Langevin et al., 2007). With LPA $_{1} /$ EGFP-transfection 


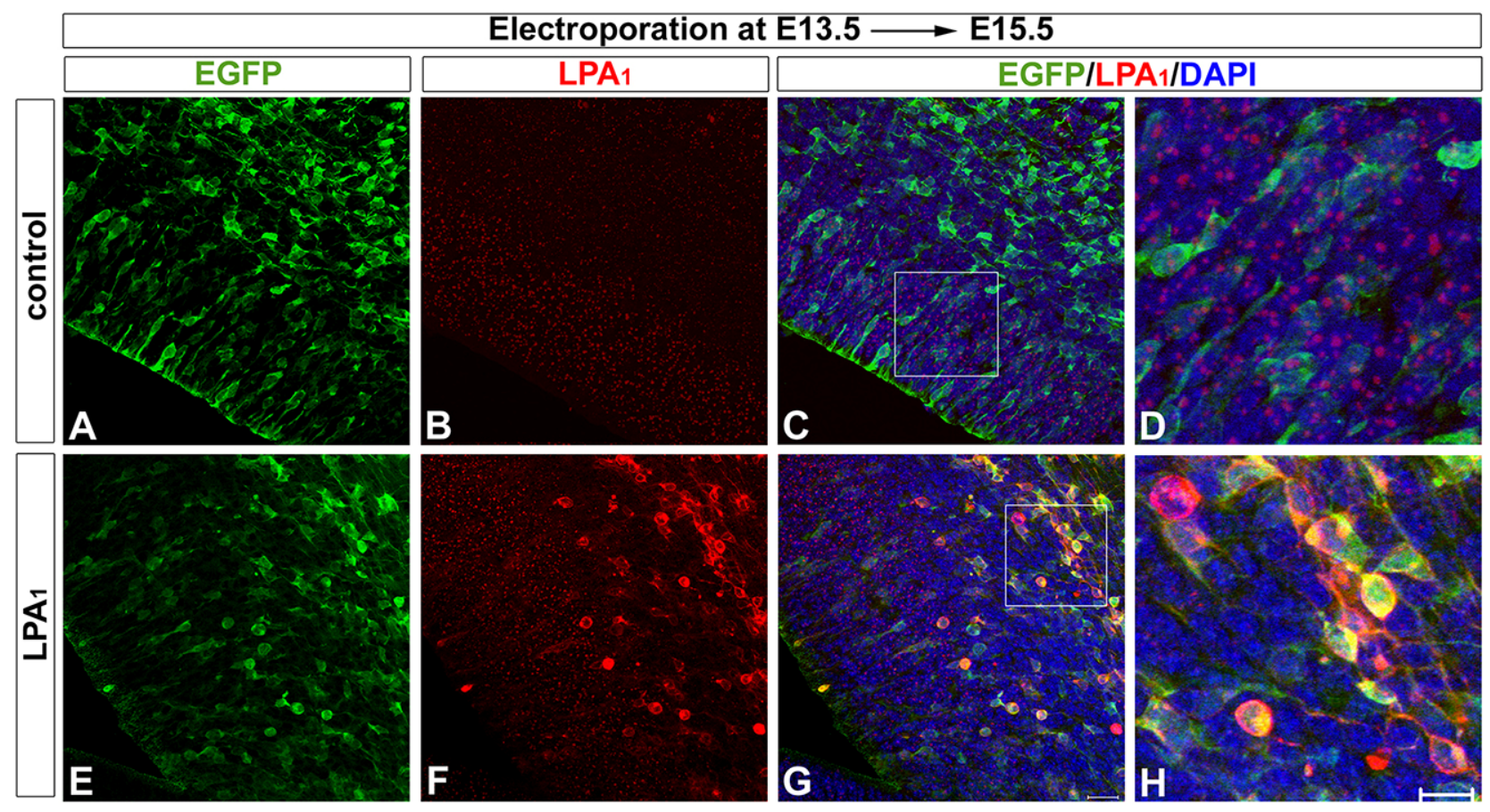

Fig. 3. Immunohistochemical localization of $L P A_{1}$ in the in utero electroporated cortices of embryonic mice. Embryonic mice cortices that were in utero electroporated at E13.5 with control (A-C; expressing EGFP) or LPA $\mathrm{A}_{1}\left(\mathrm{E}-\mathrm{G}\right.$; expressing EGFP and LPA $\mathrm{A}_{1}$ constructs and harvested at E15.5 were immunostained with anti-GFP antibody (A, E) or anti-LPA $A_{1}$ antibody (B, F). (C) Merge of $(A)$ and $(B)$. (G) Merge of $(E)$ and $(F)$. DAPI staining was used as a nuclear marker. Samples were analyzed by confocal microscopy in the following way: $10 \mathrm{z}$-stacks of each sample $(1 \mu \mathrm{m}$ apart) were taken and used to generate a two-dimensional image with Zeiss LSM software (Zeiss). Projections of these 2-D images are shown. Scale bar, $20 \mu \mathrm{m}$. (D, H) Higher magnification view of the square region in (C) and (G). Scale bar, $10 \mu \mathrm{m}$.

(Figs. 1B and 1D), $\mathrm{LPA}_{1}$ did not affect neuronal migration or neuronal morphology in developing mouse cerebral cortex. Although LPA1 overexpression appeared to slightly delay neuronal migration in $\mathrm{CP}$, it was not statistically significant. (Figs. $1 \mathrm{C}$ and $1 \mathrm{D})$. These results indicate that $\mathrm{LPA}_{1}$ overexpression in cerebral cortex did not affect radial migration of neuronal progenitor cells.

\section{Subcellular localization of LPA 1 in LPA $A_{1}$-overexpressing} mice

To delineate the subcellular localization of $\mathrm{LPA}_{1}$, we examined its protein distribution in EGFP- and LPA $/$ EGFP-transfected mice cerebral cortex. First, we tested the antibody specificity to $\mathrm{LPA}_{1}$. Western blot analysis of EGFP and LPA 1 /EGFP overexpressing TR neocortical neuroblast cells, which revealed a single band at the expected size for LPA $_{1}$ (Fig. 2), demonstrated the specificity of the antibody used to detect $L P A_{1}$. We next characterized the subcellular localization of $\mathrm{LPA}_{1}$ using immunohistochemistry (Fig. 3). At E15.5, 2 days after in utero electroporation, we performed GFP and LPA 1 double immunostaining in EGFP- and LPA A $_{1}$ EGFP-transfected mice cerebral cortex. In EGFP-transfected controls, LPA 1 did not co-localize with the GFP signal (Figs. 3A-3C). Interestingly, endogenous LPA $_{1}$ positive signal, which was observed in the nuclear/perinuclear area of neuronal cells located in the VZ, formed a spot-like

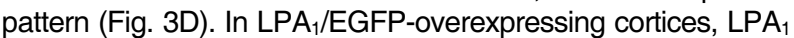
expression co-localized with GFP (Figs. 3E-3G). As shown in Fig. $3 \mathrm{H}, \mathrm{LPA}_{1}$ was mainly located in plasma membrane in
$\mathrm{LPA}_{1}$-overexpressing neuronal cells. Additionally, endogenous $\mathrm{LPA}_{1}$-positive signals were the same as those seen in EGFP transfected controls (Fig. 3G). Thus, these data show that the endogenous subcellular localization of LPA ${ }_{1}$, which exhibited a spot-like pattern, was located in the nuclear/perinuclear area, whereas the LPA 1 in LPA 1 -overexpressing cells was located in the plasma membrane.

\section{$\mathrm{LPA}_{1}$ is mainly expressed in ventricular zone of mouse embryonic cerebral cortex}

Due to the fact that our Western blotting and in utero electroporation experiment revealed that the $\mathrm{LPA}_{1}$ antibody was specific for detecting $L P A_{1}$, we further identified the $L P A_{1}$ protein expression pattern in the cerebral cortex of (E13.5 to E17.5) embryonic mice (Figs. 5 and 6). First, we identified that the Lpar1 transcript was mainly expressed in the VZ of cerebral cortex using in situ hybridization, as previously described (Hecht et al., 1996) (Fig. 4). At E13.5, Lpar1 antisense riboprobes revealed that a high level of expression of $L$ par1 was detected strictly in the VZ of cerebral cortex (Fig. 4A). At E15.5, the level of Lpar1 mRNA expression, which were exhibited in the $V Z$ were slightly diminished (Fig. 4C). At E17.5, Lpar1 mRNA in VZ was barely detectable (Fig. 4E). Immunohistochemical analysis confirmed that $\mathrm{LPA}_{1}$ was located in the cerebral cortex at E13.5 (Fig. 5). In particular, LPA 1 levels were highly enriched within the VZ (Figs. $5 \mathrm{~A}$ and $5 \mathrm{~B}$ ) and the lens (Figs. $5 \mathrm{~A}$ and $5 \mathrm{C}$ ). To examine the expression pattern of $\mathrm{LPA}_{1}$ during cortical development, we performed immunostaining on sagittal brain sections obtained 

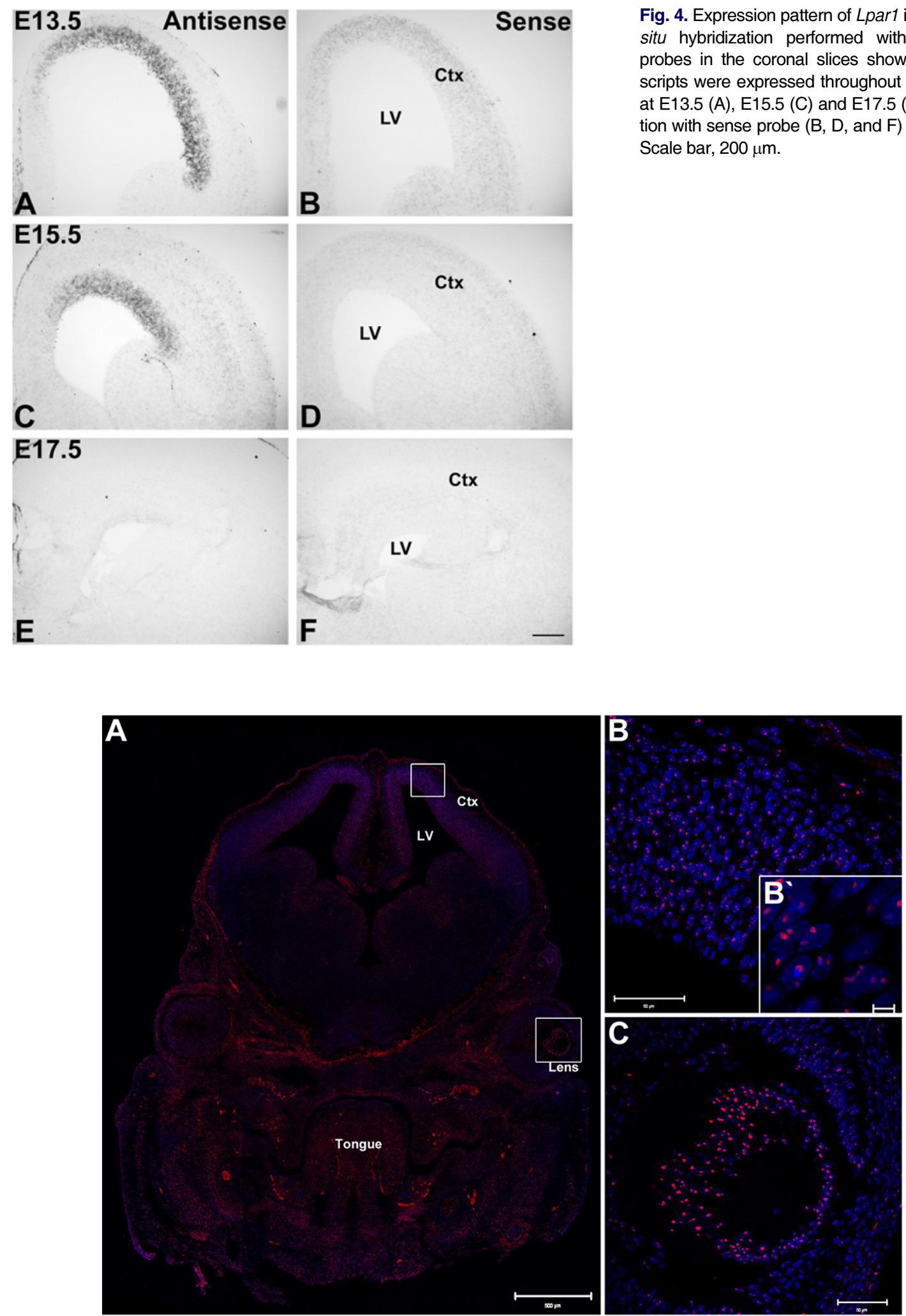

Fig. 5. Expression pattern of $L P A_{1}$ in mouse embryo 13.5 cortices. (A) The distribution of $L P A_{1}$ was examined by immunostaining with an anti$\mathrm{LPA}_{1}$ antibody (red) in fixed coronal sections of E13.5 embryonic brain. LPA 1 protein was expressed in the cells located predominately in the VZ and the lens. (B) Higher magnification view of the square in upper region of $A$. (B') Higher magnification view of (B). (C) Higher magnification view of the square in lower region of $A$. DAPI (blue) staining was used as a nuclear marker. Samples were analyzed by confocal microscopy. (A) Scale bar, $500 \mu \mathrm{m}$. (B, C) Scale bar, $50 \mu \mathrm{m}$. (B') Scale bar, $5 \mu \mathrm{m}$. Ctx, Cortex; LV, lateral ventricle. 


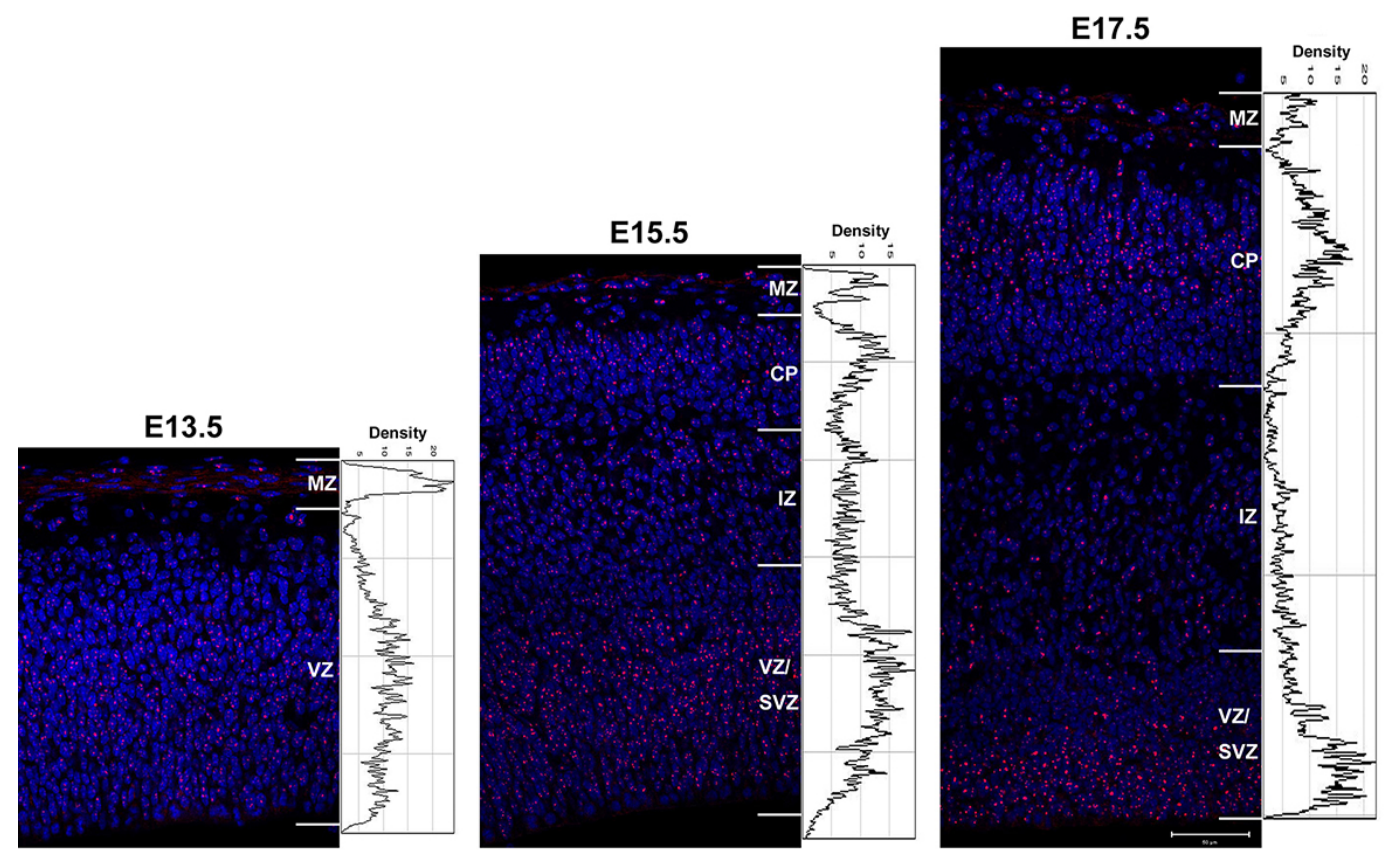

Fig. 6. Expression pattern of $\mathrm{LPA}_{1}$ during cortical development. Sagittal sections of the cortex from E13.5-E17.5 were immunostained to antiLPA1 antibody (red). DAPI (blue) staining was used as a nuclear marker. Densities of each red signal were measured by dynamic profiler plugin in ImageJ (NIH) and shown in right panel. Samples were analyzed by confocal microscopy. Scale bar, $50 \mu \mathrm{m}$. MZ, marginal zone.

from E13.5 to E17.5 mice (Fig. 6). At E13.5, immunostaining of $\mathrm{LPA}_{1}$ revealed that a high level of $\mathrm{LPA}_{1}$ was detected in the $\mathrm{VZ}$ of cerebral cortex. At E15.5, LPA ${ }_{1}$ levels were high in the VZ and the CP. At E17.5, the levels of LPA 1 were highly enriched within the VZ and upper layer of the CP. Taken together, these data demonstrate that $\mathrm{LPA}_{1}$ was expressed in the VZ and upper layer of the $\mathrm{CP}$ in the cerebral cortex of developing mice.

\section{DISCUSSION}

The aim of the present study was to characterize functional consequence of $\mathrm{LPA}_{1}$ in the developing cerebral cortex. Our results provide an additional understanding of the role of $\mathrm{LPA}_{1}$ in the developing cerebral cortex and of the technical application of in utero electroporation for the validation of antibodies.

We used in utero electroporation to uncover the role of LPA in neuronal migration from the VZ to the $C P$. The overexpression of LPA ${ }_{1}$ in newly postmitotic cells of the VZ did not show any obvious abnormality in the neuronal migration to the $C P$ (Fig. 1). LPA ${ }_{1}$, which is endogenously expressed in the VZ (Hecht et al., 1996), has an important role in the maintenance of neuroprogenitor pools in the VZ (Kingsbury et al., 2003). The LPA receptor-mediated signaling is regulated by their ligand, LPA. Thus, the levels of LPA may be low in the SVZ and IZ. Thus, the ectopic expression of LPA ${ }_{1}$ did not change neuronal migration in the cerebral cortex.

An examination of the subcellular localization of $\mathrm{LPA}_{1}$ was

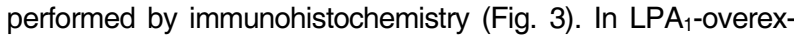
pressing cerebral cortical cells, $\mathrm{LPA}_{1}$, which colocalized with EGFP fluorescence, was predominantly expressed in the plasma membrane (Fig. $3 \mathrm{H}$ ). These results were similar to those previously reported in a study of $\mathrm{LPA}_{1}$ overexpression in a cellbased assay (Avendano-Vazquez et al., 2005; Murph et al.,
2003; Urs et al., 2005).

In EGFP expressing control cerebral cortex, $\mathrm{LPA}_{1}$ and EGFP signal did not colocalize, and the endogenous $\mathrm{LPA}_{1}$-positive signal was located in the perinuclear area and looked like an $\mathrm{LPA}_{1}$ oligomer (Fig. 3D). G protein-coupled receptor (GPCR) oligomerization has recently been widely accepted, and the number of documented oligomeric GPCR combinations is extensive (Filizola, 2010; Gurevich and Gurevich, 2008; Maggio et al., 2005; Milligan, 2009; Vidi et al., 2011). Active GPCRs are specifically phosphorylated by G-protein-coupled receptor kinases (GRKs), initiating arrestin recruitment. Receptor/arrestin complexes than recruit two components of the internalization machinery (clathrin and AP-2) and a variety of other proteins, initiating the second round of signaling (DeWire et al., 2007; Moore et al., 2007). Thus, GPCR oligomerization may be regulated by arrestin-mediated signaling (Gurevich and Gurevich, 2008). Arrestin is important in the LPA induced signaling cascade, and $\mathrm{LPA}_{1}$ internalization is regulated by arrestin mediated pathway (DeWire et al., 2007; Gesty-Palmer et al., 2005; Sun and Lin, 2008; Sun and Yang, 2010; Urs et al., 2005; 2008). Another report showed that $\mathrm{LPA}_{1}$ can dimerize (Zaslavsky et al., 2006). Our observation of ventricular zone cells that were immunopositive to LPA1 antibody with puncta morphology is intriguing. We speculate that these intracellular puncta might have been formed after LPA1 are bound to ligands (i.e., lysophosphatitic acids), followed by internalization of this receptor-ligand complex into the cells. Taken together, these results suggest that activated LPA 1 is internalized and oligomerized by arrestin scaffolding.

In a previous in situ hybridization study, the Lpar1 expression pattern was mainly located in the VZ of the cerebral cortex of developing mouse (Hecht et al., 1996). We performed in situ hybridization of Lpar1 in the cerebral cortex and found the 
same expression pattern of the Lpar1 transcript (Fig. 4). In Figs. 5 and 6 , the protein expression pattern of LPA 1 is mainly located in the VZ and the CP. During cortical development, postmitotic neurons migrate toward the $\mathrm{CP}$ from the $\mathrm{VZ}$ and pass the IZ. Within the $\mathrm{CP}$, radially migrating cells become arranged in an inside-out pattern in which the earlier generated neurons occupy deeper layers, and those generated later become located in more superficial layers (Aboitiz et al., 2001). These previous reports indicated that the transcripts of Lpar1 are located in the VZ, and $\mathrm{LPA}_{1}$-expressing cells migrate toward the CP from VZ. Thus, $\mathrm{LPA}_{1}$ protein is located in the VZ and $\mathrm{CP}$ of the cerebral cortex of mice. This observation requires further studies with functional consequence of $\mathrm{LPA}_{1}$ expressed in VZ and CP.

Nowadays, in utero electroporation is a widely used and well established experimental method. It has a several advantage like region-specific, cell type-specific, inducible, and multiple gene targeting. Moreover, it can apply to region dependent behaviors and functional outcome test (De Vry et al., 2010; Taniguchi et al., 2012). Besides the above advantages of the in utero electroporation, it can easily introduce specific genes in vivo condition. Despite many targeted GPCR antibody is available but can't easily find validated antibody, for this reason in utero electroporation is a powerful tools for quick and easily find good antibody from hardly discern GPCR.

In summary, our results provide information on the subcellular localization and tissue distribution of LPA ${ }_{1}$ and the technical advantages of the use of in utero electroporation for the validation of antibodies.

\section{ACKNOWLEDGMENTS}

We thank Dr. Jerold Chun for providing Lpar1 riboprobe. We are grateful to Dr. Haeyoung Suh-Kim and Rae-Hee Park for technical support of in utero electroporation. We are grateful to Seung-Hae Kwon at the Chuncheon Center of the Korea Basic Science Institute for technical assistance in confocal image analyses (LSM 510 META NLO). This work was supported by grants from National Research Foundation of Korea (NRF2013M3C7A1056565, NRF-2009-0094071, and NRF-20100013043) and a grant from Hallym University (HRF-201401-015).

\section{REFERENCES}

Aboitiz, F., Morales, D., and Montiel, J. (2001). The inverted neurogenetic gradient of the mammalian isocortex: development and evolution. Brain Res. Brain Res. Rev. 38, 129-139.

An, S., Bleu, T., Hallmark, O.G., and Goetzl, E.J. (1998). Characterization of a novel subtype of human $\mathrm{G}$ protein-coupled receptor for lysophosphatidic acid. J. Biol. Chem. 273, 7906-7910.

Avendano-Vazquez, S.E., Garcia-Caballero, A., and Garcia-Sainz, J.A. (2005). Phosphorylation and desensitization of the lysophosphatidic acid receptor LPA1. Biochem. J. 385, 677-684.

Bandoh, K., Aoki, J., Hosono, H., Kobayashi, S., Kobayashi, T., Murakami-Murofushi, K., Tsujimoto, M., Arai, H., and Inoue, K. (1999). Molecular cloning and characterization of a novel human G-protein-coupled receptor, EDG7, for lysophosphatidic acid. J. Biol. Chem. 274, 27776-27785.

Cheng, Y., Makarova, N., Tsukahara, R., Guo, H., Shuyu, E., Farrar, P., Balazs, L., Zhang, C., and Tigyi, G. (2009). Lysophosphatidic acid-induced arterial wall remodeling: requirement of PPARgamma but not LPA1 or LPA2 GPCR. Cell. Signal. 21, 1874-1884.

Choi, J.W., Herr, D.R., Noguchi, K., Yung, Y.C., Lee, C.W., Mutoh, T., Lin, M.E., Teo, S.T., Park, K.E., Mosley, A.N., et al. (2010). LPA receptors: subtypes and biological actions. Annu. Rev. Pharmacol. Toxicol. 50, 157-186.

Chun, J., and Jaenisch, R. (1996). Clonal cell lines produced by infection of neocortical neuroblasts using multiple oncogenes transduced by retroviruses. Mol. Cell. Neurosci. 7, 304-321.
Contos, J.J., Fukushima, N., Weiner, J.A., Kaushal, D., and Chun, J. (2000). Requirement for the IpA1 lysophosphatidic acid receptor gene in normal suckling behavior. Proc. Natl. Acad. Sci. USA 97, 13384-13389.

De Vry, J., Martinez-Martinez, P., Losen, M., Temel, Y., Steckler, T., Steinbusch, H.W., De Baets, M.H., and Prickaerts, J. (2010). In vivo electroporation of the central nervous system: a non-viral approach for targeted gene delivery. Prog. Neurobiol. 92, 227244.

DeWire, S.M., Ahn, S., Lefkowitz, R.J., and Shenoy, S.K. (2007). Beta- arrestins and cell signaling. Annu. Rev. Physiol. 69, 483-510.

Estivill-Torrus, G., Llebrez-Zayas, P., Matas-Rico, E., Santin, L., Pedraza, C., De Diego, I., Del Arco, I., Fernandez-Llebrez, P., Chun, J., and De Fonseca, F.R. (2008). Absence of LPA1 signaling results in defective cortical development. Cereb. Cortex $18,938-950$

Filizola, M. (2010). Increasingly accurate dynamic molecular models of G-protein coupled receptor oligomers: Panacea or Pandora's box for novel drug discovery? Life Sci. 86, 590-597.

Fukushima, N., Weiner, J.A., and Chun, J. (2000). Lysophosphatidic acid (LPA) is a novel extracellular regulator of cortical neuroblast morphology. Dev. Biol. 228, 6-18.

Gesty-Palmer, D., El Shewy, H., Kohout, T.A., and Luttrell, L.M. (2005). beta-Arrestin 2 expression determines the transcriptional response to lysophosphatidic acid stimulation in murine embryo fibroblasts. J. Biol. Chem. 280, 32157-32167.

Gobeil, F., Jr., Bernier, S.G., Vazquez-Tello, A., Brault, S., Beauchamp, M.H., Quiniou, C., Marrache, A.M., Checchin, D., Sennlaub, F., Hou, X., et al. (2003). Modulation of pro-inflammatory gene expression by nuclear lysophosphatidic acid receptor type1. J. Biol. Chem. 278, 38875-38883.

Gurevich, V.V., and Gurevich, E.V. (2008). GPCR monomers and oligomers: it takes all kinds. Trends Neurosci. 31, 74-81.

Hecht, J.H., Weiner, J.A., Post, S.R., and Chun, J. (1996). Ventricular zone gene-1 (vzg-1) encodes a lysophosphatidic acid receptor expressed in neurogenic regions of the developing cerebral cortex. J. Cell Biol. 135, 1071-1083.

Ishii, I., Fukushima, N., Ye, X., and Chun, J. (2004). Lysophospholipid receptors: signaling and biology. Annu. Rev. Biochem. 73, 321-354.

Kim, J., Keys, J.R., and Eckhart, A.D. (2006). Vascular smooth muscle migration and proliferation in response to lysophosphatidic acid (LPA) is mediated by LPA receptors coupling to Gq. Cell. Signal. 18, 1695-1701.

Kingsbury, M.A., Rehen, S.K., Contos, J.J., Higgins, C.M., and Chun, J. (2003). Non-proliferative effects of lysophosphatidic acid enhance cortical growth and folding. Nat. Neurosci. 6, 12921299.

Kotarsky, K., Boketoft, A., Bristulf, J., Nilsson, N.E., Norberg, A. Hansson, S., Owman, C., Sillard, R., Leeb-Lundberg, L.M., and Olde, B. (2006). Lysophosphatidic acid binds to and activates GPR92, a G protein-coupled receptor highly expressed in gastrointestinal lymphocytes. J. Pharmacol. Exp. Ther. 318, 619-628.

Langevin, L.M., Mattar, P., Scardigli, R., Roussigne, M., Logan, C., Blader, P., and Schuurmans, C. (2007). Validating in utero electroporation for the rapid analysis of gene regulatory elements in the murine telencephalon. Dev. Dyn. 236, 1273-1286.

Lee, C.W., Rivera, R., Gardell, S., Dubin, A.E., and Chun, J. (2006). GPR92 as a new G12/13- and Gq-coupled lysophosphatidic acid receptor that increases CAMP, LPA5. J. Biol. Chem. 281, 23589-23597.

Liszewska, E., Reinaud, P., Billon-Denis, E., Dubois, O., Robin, P., and Charpigny, G. (2009). Lysophosphatidic acid signaling during embryo development in sheep: involvement in prostaglandin synthesis. Endocrinology 150, 422-434.

Maggio, R., Novi, F., Scarselli, M., and Corsini, G.U. (2005). The impact of G-protein-coupled receptor hetero-oligomerization on function and pharmacology. FEBS J. 272, 2939-2946.

Matas-Rico, E., Garcia-Diaz, B., Llebrez-Zayas, P., Lopez-Barroso, D., Santin, L., Pedraza, C., Smith-Fernandez, A., FernandezLlebrez, P., Tellez, T., Redondo, M., et al. (2008). Deletion of lysophosphatidic acid receptor LPA1 reduces neurogenesis in the mouse dentate gyrus. Mol. Cell. Neurosci. 39, 342-355.

Matsuda, T., and Cepko, C.L. (2004). Electroporation and RNA interference in the rodent retina in vivo and in vitro. Proc. Natl. Acad. Sci. USA 101, 16-22. 
Milligan, G. (2009). G protein-coupled receptor hetero-dimerization: contribution to pharmacology and function. Br. J. Pharmacol. 158, 5-14.

Moolenaar, W.H., van Meeteren, L.A., and Giepmans, B.N. (2004). The ins and outs of lysophosphatidic acid signaling. Bioessays 26, 870-881.

Moore, C.A., Milano, S.K., and Benovic, J.L. (2007). Regulation of receptor trafficking by GRKs and arrestins. Annu. Rev. Physiol. 69, 451-482.

Moughal, N.A., Waters, C., Sambi, B., Pyne, S., and Pyne, N.J. (2004). Nerve growth factor signaling involves interaction between the Trk $A$ receptor and lysophosphatidate receptor 1 systems: nuclear translocation of the lysophosphatidate receptor 1 and Trk A receptors in pheochromocytoma 12 cells. Cell. Signal. $16,127-136$.

Murph, M.M., Scaccia, L.A., Volpicelli, L.A., and Radhakrishna, H. (2003). Agonist-induced endocytosis of lysophosphatidic acidcoupled LPA1/EDG-2 receptors via a dynamin2- and Rab5dependent pathway. J. Cell Sci. 116, 1969-1980.

Noguchi, K., Ishii, S., and Shimizu, T. (2003). Identification of p2y9/ GPR23 as a novel G protein-coupled receptor for lysophosphatidic acid, structurally distant from the Edg family. J. Biol. Chem. 278, 25600-25606.

Pasternack, S.M., von Kugelgen, I., Aboud, K.A., Lee, Y.A., Ruschendorf, F., Voss, K., Hillmer, A.M., Molderings, G.J., Franz, T., Ramirez, A., et al. (2008). G protein-coupled receptor P2Y5 and its ligand LPA are involved in maintenance of human hair growth. Nat. Genet. 40, 329-334.

Saito, T. (2006). In vivo electroporation in the embryonic mouse central nervous system. Nat. Protoc. 1, 1552-1558.

Spohr, T.C., Choi, J.W., Gardell, S.E., Herr, D.R., Rehen, S.K., Gomes, F.C., and Chun, J. (2008). Lysophosphatidic acid receptor-dependent secondary effects via astrocytes promote neuronal differentiation. J. Biol. Chem. 283, 7470-7479.

Sun, J., and Lin, X. (2008). Beta-arrestin 2 is required for lysophosphatidic acid-induced NF-kappaB activation. Proc. Natl. Acad. Sci. USA $105,17085-17090$.
Sun, W., and Yang, J. (2010). Molecular basis of lysophosphatidic acid-induced NF-kappaB activation. Cell. Signal. 22, 1799-1803.

Sun, Y., Nam, J.S., Han, D.H., Kim, N.H., Choi, H.K., Lee, J.K., Rhee, H.J., and Huh, S.O. (2010). Lysophosphatidic acid induces upregulation of Mcl-1 and protects apoptosis in a PTXdependent manner in H19-7 cells. Cell. Signal. 22, 484-494.

Taniguchi, Y., Young-Pearse, T., Sawa, A., and Kamiya, A. (2012). In utero electroporation as a tool for genetic manipulation in vivo to study psychiatric disorders: from genes to circuits and behaviors. Neuroscientist 18, 169-179.

Urs, N.M., Jones, K.T., Salo, P.D., Severin, J.E., Trejo, J., and Radhakrishna, H. (2005). A requirement for membrane cholesterol in the beta-arrestin- and clathrin-dependent endocytosis of LPA1 Iysophosphatidic acid receptors. J. Cell Sci. 118, 5291-5304.

Urs, N.M., Kowalczyk, A.P., and Radhakrishna, H. (2008). Different mechanisms regulate lysophosphatidic acid (LPA)-dependent versus phorbol ester-dependent internalization of the LPA1 receptor. J. Biol. Chem. 283, 5249-5257.

Vidi, P.A., Ejendal, K.F., Przybyla, J.A., and Watts, V.J. (2011). Fluorescent protein complementation assays: new tools to study G protein-coupled receptor oligomerization and GPCR-mediated signaling. Mol. Cell. Endocrinol. 331, 185-193.

Waters, C.M., Saatian, B., Moughal, N.A., Zhao, Y., Tigyi, G., Natarajan, V., Pyne, S., and Pyne, N.J. (2006). Integrin signalling regulates the nuclear localization and function of the lysophosphatidic acid receptor-1 (LPA1) in mammalian cells. Biochem. J. 398, 55-62.

Yung, Y.C., Stoddard, N.C., and Chun, J. (2014). LPA receptor signaling: pharmacology, physiology, and pathophysiology. J. Lipid Res. 55, 1192-1214.

Zaslavsky, A., Singh, L.S., Tan, H., Ding, H., Liang, Z., and Xu, Y. (2006). Homo- and hetero-dimerization of LPA/S1P receptors, OGR1 and GPR4. Biochim. Biophys. Acta 1761, 1200-1212.

Zheng, Y., Kong, Y., and Goetzl, E.J. (2001). Lysophosphatidic acid receptor-selective effects on Jurkat $T$ cell migration through a Matrigel model basement membrane. J. Immunol. 166, 23172322. 